\title{
A novel silkworm pupae carboxymethyl chitosan inhibits mouse L929 fibroblast proliferation
}

\author{
Lin Zhu, Zuo-Qing Fan, Xin-Qin Shi, Na Wang, Ying-Ying Bo, Hong-En Guo* \\ Shandong Institute of Sericulture, Yantai 264001 China \\ *Corresponding author, e-mail: guohongen@shandong.cn
}

Received 9 Jul 2019

Accepted 4 Jan 2020

\begin{abstract}
Postoperative intestinal adhesions are common and serious complications after surgery that can cause pain and potential mortality. Our previous study confirmed that silkworm pupae carboxymethyl chitosan (SP-carboxymethyl chitosan) reduced postoperative adhesion in vivo. Here, we elucidated the inhibitory effects of SP-carboxymethyl chitosan on mouse L929 fibroblasts. Cells were exposed to SP-carboxymethyl chitosan for $72 \mathrm{~h}$, then the inhibitory effects were assessed via transforming growth factor- $\beta_{1}$ (TGF- $\left.\beta_{1}\right) /$ Smads, plasminogen activator inhibitor 1 (PAI- 1 ), and tissue-type plasminogen activator (t-PA) signaling. The results showed that SP-carboxymethyl chitosan suppressed cell hyperplasia and significantly attenuated the gene and protein expressions of the TGF- $\beta_{1} /$ Smads signaling pathways. We also confirmed that t-PA/PAI-1 greatly increased for all SP-carboxymethyl chitosan-treated groups compared to the control. These findings suggest that SP-carboxymethyl chitosan may affect L929 cell proliferation through the TGF- $\beta_{1} /$ Smads signaling pathway to prevent adhesion after an operation.
\end{abstract}

KEYWORDS: carboxymethyl chitosan, mouse L929 fibroblasts, TGF- $\beta_{1} /$ Smad signaling pathway

\section{INTRODUCTION}

The formation of postoperative adhesions represents one of the most common complications after surgery, and it increases the difficulty of reoperation. Postoperative adhesion not only creates large financial burdens but also results in morbidities such as chronic pain, female infertility, and bowel obstruction [1]. Thus, preventing postoperative adhesions is a major goal in the field of surgical medicine. Postoperative adhesions are closely related to the proliferation of fibers at the site of tissue injury. Currently, the methods used to prevent adhesions are mainly the use of a physical barrier and prevention and control via drugs [2]. Although some progress has been made, better methods of preventing adhesions are urgently needed.

The postoperative adhesion pathogenesis is still not fully elaborated. Most researchers agree that injury promotes oxidative stress response, inflammation and fibrosis, also stimulates numerous pathological molecular pathway, and eventually triggers extracellular matrix accumulation [3-5]. TGF- $\beta_{1}$, a predominant pathogenic factor, regulates tissue repair through the canonical signaling pathway by phosphorylating and activating the Smad2 and Smad3 [6]. It is known that intraperitoneal fibrinolytic activity is mainly controlled by the balance of
t-PA and PAI-1. t-PA leads to the conversion of plasminogen into plasmin, which effectively degrades fibrin into fibrin degradation products; however, PAI-1 antagonizes and forms inactive complexes with t-PA [7]. In addition, TGF- $\beta_{1}$ is highly secreted after tissue injury, which could increase the expression of PAI-1, destroy the balance of t-PA/PAI-1, inhibit the degradation of fibrin, and ultimately lead to adhesion formation [3].

Chitosan, a natural polymer derived from chitin, is the second most abundant polysaccharide after cellulose [8]. Carboxymethylation for producing water-soluble derivatives of chitosan is the most common and effective method in the world. Carboxymethyl chitosan (CM-chitosan) has been used for various biomedical applications due to its unique physicochemical and biological properties [9]. Early in the 1990s, CM-chitosan was found to be able to prevent adhesion and did not need reoperation for removal due to the fact that it could be degraded and absorbed in vivo [10]. Chen et al [11] found that CM-chitosan can reduce the ratio of type I/III collagen in keloid fibroblasts by inhibiting the secretion of collagen type I while having no effect on the secretion of collagen types I and III in normal skin fibroblasts. Other studies have proved that the carboxylmethyl groups of CM-chitosan play an important role in inhibiting the proliferation of 
keloid fibroblasts by analyzing the different effects of chitosan and CM-chitosan solutions/nanoparticles on the proliferation of keloid fibroblasts [12]. Xia et al [13] fabricated a biodegradable barrier in which a poly (lactide-co-glycolide)/poly(lactide)b-poly(ethylene glycol) (PLGA/PLA-b-PEG) electrospun layer was sandwiched between layers of a carboxymethyl chitosan sponge. The electrospun layer inhibited the adhesion and spread of fibroblasts, which effectively prevented adhesion. ZahirJouzdani et al [14] analyzed the inhibition effect of chitosan (CS) and thiolated chitosan (TCS) nanoparticles and solutions on fibroblast proliferation, extracellular matrix (ECM) deposition, and pro-fibrotic cytokine expression. The results showed that CS and TCS exhibited unexpected anti-fibrotic effects both in the nanoparticle and solution. They can also inhibit the expression of two main profibrotic growth factors, $\mathrm{TGF} \beta_{1}$ and platelet-derived growth factor (PDGF). Fibroblast cell inhibition would play a great role in preventing postoperative adhesions in biomedical applications. Many experiments have shown that carboxymethyl chitosan prevents adhesion by inhibiting fibroblast proliferation in many animal models during surgery, such as abdominal operations [15], cardiac surgery $[16,17]$, and cardiovascular reoperations $[18,19]$.

Silkworm pupae are most suitable for preparation of pharmaceutical grade chitosan. In addition, most anti-adhesion drugs are expensive, so we urgently need to develop the cheaper and more effective products. We previously used silkworm pupae to create a novel SP-carboxymethyl chitosan [20] and demonstrated that it effectively reduces postoperative adhesion in a rat cecal abrasion model [21]. In the present study, we further investigated the anti-fibrotic effects of silkworm pupae carboxymethyl chitosan in mouse L929 fibroblasts.

\section{MATERIALS AND METHODS}

\section{Materials}

Silkworm pupae were from the Shandong Institute of Sericulture. Mouse L929 fibroblasts were purchased from Chinese Academy of Sciences. The culture medium was $90 \%$ DMEM $+10 \% \mathrm{FBS}$, and cells were cultured in an incubator at $37^{\circ} \mathrm{C}, 5 \% \mathrm{CO}_{2}$, and saturated humidity. 3-(4,5-dimethyl-2-thiazolyl)2,5-diphenyl-2H-tetrazolium bromide (MTT) was purchased from Amresco Co., Ltd, USA. DMSO was purchased from Shanghai Jiuyi Chemical Reagent Co., Ltd, China. TRIzol Reagent was purchased from Invitrogen, Carlsbad, USA. High-Capacity cDNA Re- verse Transcription Kit was purchased from Thermo Fisher Scientific. The whole protein extraction kit, bicinchoninic acid (BCA) protein assay kit, PVDF transfer membrane, and Tris-buffered saline with Tween (TBST) were purchased from NanJing KeyGen Biotech Co., Ltd, China. Rabbit anti-rat antibodies against TGF- $\beta_{1}$, Smad2, Smad3, and PAI-1 were purchased from NanJing KeyGen Biotech Co., Ltd, China. The t-PA antibody was purchased from Boster Biological Technology Co., Ltd, China. Secondary anti-rabbit antibody was purchased from NanJing KeyGen Biotech Co., Ltd, China. The ECL Kit was purchased from NanJing KeyGen Biotech Co., Ltd, China.

\section{SP-carboxymethyl chitosan preparation}

The specific methods for preparation were described in detail in previous studies $[13,14]$. Dry silkworm pupae powder was added to an extraction vessel followed by the addition of hexane. The organic solvent was removed, resulting in the production of defatted pupae powder. Next, silkworm pupae chitin was isolated from the defatted pupae powder by deproteinization, demineralization, and decoloration treatments. The chitin powder was treated by temperature cycling three times to obtain silkworm pupae chitosan. The chitosan powder was soaked in ethanol at room temperature for $12 \mathrm{~h}$, and then $50 \% \mathrm{NaOH}$ was added to alkalize the chitosan. Finally, N,O-carboxymethyl chitosan was generated by reacting chitosan and chloroacetic acid under alkaline conditions for $4 \mathrm{~h}$ at $70^{\circ} \mathrm{C}$.

\section{Cell culture and treatment}

The cells were incubated at $37^{\circ} \mathrm{C}$ under a $5 \% \mathrm{CO}_{2}$ atmosphere and cultured in DMEM containing $10 \%$ FBS. Cells were seeded in a 96-well plate at a density of $5 \times 10^{4} / \mathrm{ml}$ for $24 \mathrm{~h}$. Cells of the control group were cultured in DMEM. For MTT assays, the cells were treated with different concentrations of SPcarboxymethyl chitosan for 48 and $72 \mathrm{~h}$. Three replicates were included for each group. Three concentrations $(1.25,5$, and $20 \mathrm{mg} / \mathrm{ml})$ were tested by MTT for subsequent experiments.

\section{Proliferation of fibroblasts}

The different concentrations of SP-carboxymethyl chitosan were $0.01,0.02,0.04,0.08,0.16,0.31$, $0.63,1.25,2.5,5$, and $10 \mathrm{mg} / \mathrm{ml}$. After treatment, $20 \mu \mathrm{l}(5 \mathrm{mg} / \mathrm{ml})$ MTT was added to each group and incubated at $37^{\circ} \mathrm{C}$ under a $5 \% \mathrm{CO}_{2}$ atmosphere for $4 \mathrm{~h}$. Then the liquid supernatant was removed, and $150 \mu \mathrm{l}$ DMSO reagent was added to each group and 
shaken well for $10 \mathrm{~min}$. The absorbance was detected at $490 \mathrm{~nm}$ using a microplate reader (BioTek ELx800, USA) to determine the number of viable cells. The percentage of viability was calculated from the following formula.

$$
\text { Inhibition rate }(\%)=\frac{\mathrm{OD}_{\mathrm{con}}-\mathrm{OD}_{\exp }}{\mathrm{OD}_{\exp }} \times 100 \text {, }
$$

where $\mathrm{OD}_{\text {con }}$ and $\mathrm{OD}_{\exp }$ are values from normal control group and experimental group, respectively.

At indicated time points, the morphology of the cells was observed under a phase contrast microscope (Olympus IX 51, Tokyo, Japan).

\section{Transmission electron microscopy (TEM)}

Cells were rinsed with warm PBS and collected in an EP tube. The cells were fixed with 2.5\% glutaraldehyde for $2 \mathrm{~h}$ or longer and then rinsed with $0.1 \mathrm{M}$ phosphate buffer 3 times, followed by fixing with $0.1 \%$ osmium acid for $2-3 \mathrm{~h}$. After that, cells were dehydrated by ethyl alcohol and acetone according to standard procedures. After embedding and solidifying, the cells were cut into slices $(50-60 \mathrm{~nm})$ by an LKB-1 Ultra-thin Slicer. Cells were stained with $3 \%$ uranyl acetate and lead citrate. Finally, they were observed under the TEM.

\section{Real-time PCR analysis}

Cells were collected and total RNA was extracted by using TRIzol Reagent according to the manufacturer's instructions. Two micrograms of total RNA were reverse transcribed into cDNA using a High-Capacity cDNA Reverse Transcription Kit. Real-time PCR was performed by using Real-time PCR Master Mix (SYBR Green; QTOYOBO, Japan) on an ABI Step One Plus Realtime PCR system (USA). The target genes and associated primers were as follows: GAPDH forward, 5-TATGTCGTGGAGTCTACTGGT-3; GAPDH reverse, 5-GAGTTGTCATATTTCTCGTGG-3; TGF- $\beta_{1}$ forward, 5-AGGGCTACCATGCCAACTTC-3; TGF- $\beta_{1}$ reverse, 5-CCACGTAGTAGACGATGGGC-3; Smad2 forward, 5-GTGCCTCACGCCTAACGG-3; Smad2 reverse, 5-CGGTAAATCTACCCTCCGGG-3; Smad3 forward, 5-CTACTGCCACTTGGAGTCTCG-3; Smad3 reverse, 5-TCGCCCGAACTTCGCTTTTA-3; $t$-PA forward, 5-TCGGGACACAGAAGAAACGG-3; $t$-PA reverse, 5-TTGTCTGCGTTGGCTCATCT-3; PAI-1 forward, 5-GGCCAATGGAAGACCCCTTT-3; and PAI-1 reverse, 5-GCTGGTAGGGCAGTTCCAC-3. Real-time PCR for each gene was performed in triplicate. To $0.1 \mathrm{ml}$ PCR tube, the following components were

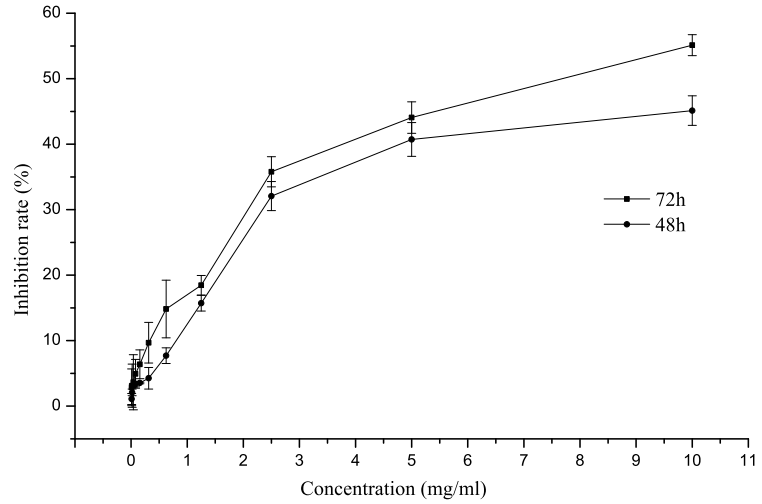

Fig. 1 Effects of SP-carboxymethyl chitosan on cell proliferation.

added in turn: $10 \mu 12 \mathrm{X}$ Realltime PCR Master Mix (SYBR Green); $1 \mu \mathrm{l}$ cDNA Templates $(0.2 \mu \mathrm{g}) ; 2 \mu \mathrm{l}$ Primers $(10 \mu \mathrm{M})$; and $7 \mu 10.1 \%$ DEPC. The relative expression levels of target genes were determined by the $2^{-\Delta \Delta C T}$ method.

\section{Western blotting (WB)}

Cells were collected and extracted with a whole protein extraction kit containing lysis buffer and a protease and phosphatase inhibitor cocktail. The protein concentration of the cell lysate was determined using the BCA protein assay kit according to the manufacturer's instructions. Protein lysate samples were electrophoresed on $10 \%$ sodium dodecyl sulfate polyacrylamide gels and transblotted onto a PVDF transfer membrane. The membranes were blocked in TBST and 5\% (v/v) nonfat milk for $1.5-2 \mathrm{~h}$ at room temperature, washed three times, and then incubated in rabbit anti-rat GAPDH, TGF- $\beta_{1}$, Smad2, Smad3, t-PA, or PAI-1 antibodies (1:1000) overnight at $4^{\circ} \mathrm{C}$. After washing three times with TBST, the membranes were combined with secondary anti-rabbit antibody for $1-2 \mathrm{~h}$ at $37^{\circ} \mathrm{C}$. The protein bands were colored using the ECL Kit, and the band densities were scanned and calculated with GEL-PRO32 software.

\section{Statistical analysis}

All statistical calculations were performed using ORIGIN 8.5 software. Date were analyzed with oneway ANOVA.

\section{RESULTS}

\section{Fibroblast proliferation}

To measure the change of proliferation of fibroblasts with different concentrations of SP-carboxymethyl 


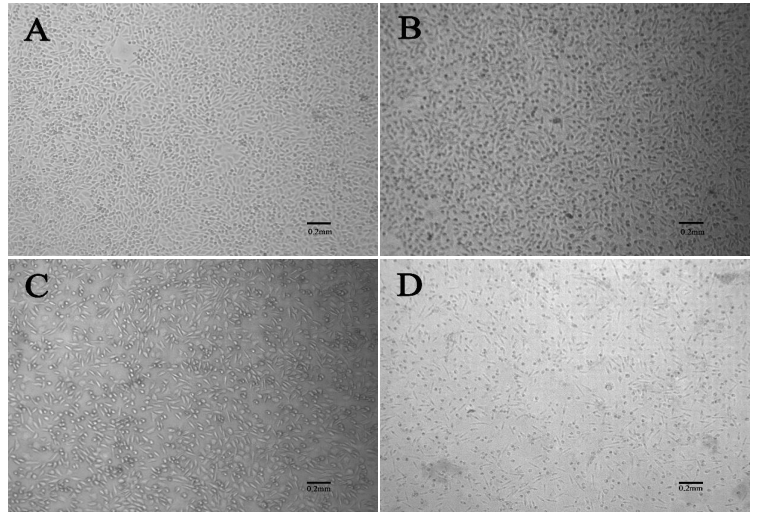

Fig. 2 Effects of SP-carboxymethyl chitosan on cell morphology ( $\times 200$ ): (A) control group; (B) $1.25 \mathrm{mg} / \mathrm{ml}$; (C) $5 \mathrm{mg} / \mathrm{ml}$; and (D) $20 \mathrm{mg} / \mathrm{ml}$.

chitosan treatment, we analyzed the inhibition rate by MTT assays. The results (Fig. 1) indicate that the inhibition rate of all treatment groups did not exceed $50 \%$ when treated for $48 \mathrm{~h}$. However, when the concentration of SP-carboxymethyl chitosan was more than $5 \mathrm{mg} / \mathrm{ml}$ for $72 \mathrm{~h}$, the inhibition rate increased linearly and was more than $50 \%$. Based on the above results, three concentrations $(1.25,5$, and $20 \mathrm{mg} / \mathrm{ml}$ ) were chosen for subsequent experiments, and all groups were treated for $72 \mathrm{~h}$ for subsequent tests.

\section{Microscopic observation of fibroblast morphology}

Fig. 2 shows microscopic images $(\times 200)$ of cells obtained after $72 \mathrm{~h}$ of incubation with blank and three concentrations $(1.25,5$, and $20 \mathrm{mg} / \mathrm{ml})$ of SP-carboxymethyl chitosan. Cells with normal morphology (bulky, abundant cytoplasm, flat shaped, and irregular fibrous arrangements) were observed in the control group. Cells in SP-carboxymethyl chitosan treatment groups became smaller, partially exfoliated, and suspended in the culture medium, and when compared with the control group, their density and quantity were decreased. These results were in accord with the proliferation results shown in Fig. 1.

\section{TEM observation of cell microstructure}

We used TEM to observe the influence on cell microstructures after SP-carboxymethyl chitosan treatment. As displayed in Fig. 3, mitochondrial morphology of cells in the control group and those treated with $1.25 \mathrm{mg} / \mathrm{ml} \mathrm{SP-carboxymethyl} \mathrm{chitosan}$ showed little change, but mitochondrial vacuolation

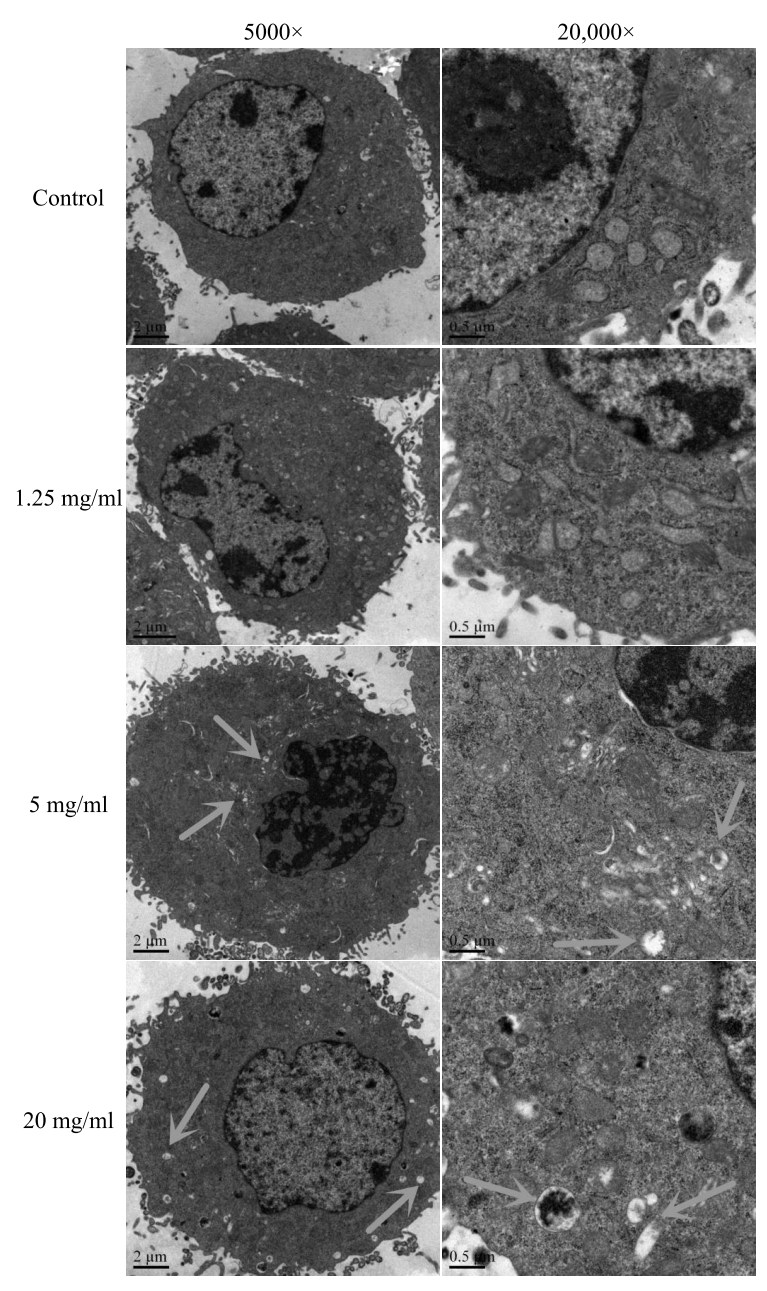

Fig. 3 Effects of SP-carboxymethyl chitosan on cell microstructure $(\times 5000, \times 20000)$. The arrows indicate mitochondrial.

and denaturation (as indicated by the arrows) were occasionally observed in $5 \mathrm{mg} / \mathrm{ml}$ and $20 \mathrm{mg} / \mathrm{ml}$ SP-carboxymethyl chitosan treatment groups. There were no significant changes in the Golgi, endoplasmic reticulum, and ribosomes in any group (data were not visible).

\section{SP-carboxymethyl chitosan regulates the TGF- $\beta_{1} /$ Smad signaling pathway during cell fibrogenesis}

To test whether stimulation with SP-carboxymethyl chitosan was correlated with cell fibrogenesis gene expression, we assessed TGF- $\beta_{1}$, Smad2, Smad3, t-PA, and PAI-1 mRNA levels by RT-PCR (Table 1). The expressions of TGF- $\beta_{1}$ and PAI- 1 were downregulated in all SP-carboxymethyl chitosan-treated groups compared to the control $(p<0.01)$. Addi- 
Table 1 Effects of SP-carboxymethyl chitosan on the expression of genes in the TGF- $\beta_{1} /$ Smad signaling pathway.

\begin{tabular}{lccccc}
\hline Group & TGF- $\beta_{1}$ & Smad2 & Smad3 & t-PA & PAI-1 \\
\hline Control & $1.008 \pm 0.158$ & $1.001 \pm 0.046$ & $1.001 \pm 0.061$ & $1.000 \pm 0.029$ & $1.001 \pm 0.050$ \\
$1.25 \mathrm{mg} / \mathrm{ml}$ & $0.893 \pm 0.130^{* * *}$ & $0.780 \pm 0.009^{* * *}$ & $0.781 \pm 0.065^{* *}$ & $1.382 \pm 0.086^{* *}$ & $0.649 \pm 0.049^{* * *}$ \\
$5 \mathrm{mg} / \mathrm{ml}$ & $0.488 \pm 0.054^{* *}$ & $0.577 \pm 0.038^{* *}$ & $0.614 \pm 0.091^{* *}$ & $1.936 \pm 0.172^{* *}$ & $0.432 \pm 0.016^{* * *}$ \\
$20 \mathrm{mg} / \mathrm{ml}$ & $0.280 \pm 0.049^{* *}$ & $0.178 \pm 0.022^{* *}$ & $0.469 \pm 0.034^{* *}$ & $2.532 \pm 0.291^{* *}$ & $0.331 \pm 0.014^{* *}$ \\
\hline
\end{tabular}

$* p<0.05$ and $* * p<0.01$ versus control group.

Control $1.25 \mathrm{mg} / \mathrm{mL} 5 \mathrm{mg} / \mathrm{mL} 20 \mathrm{mg} / \mathrm{mL}$

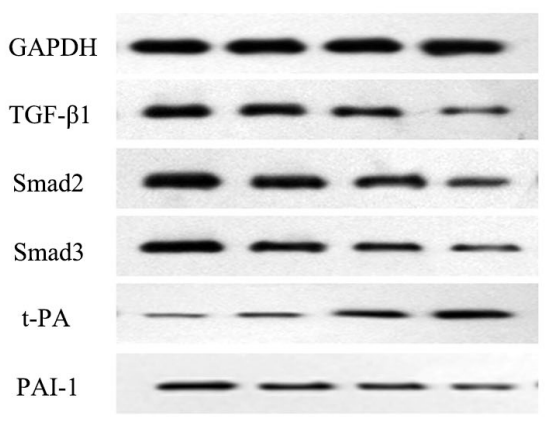

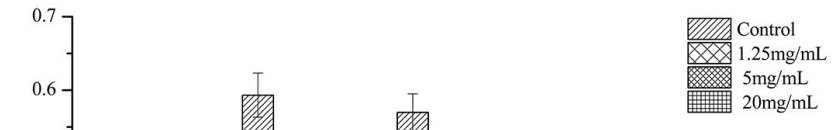

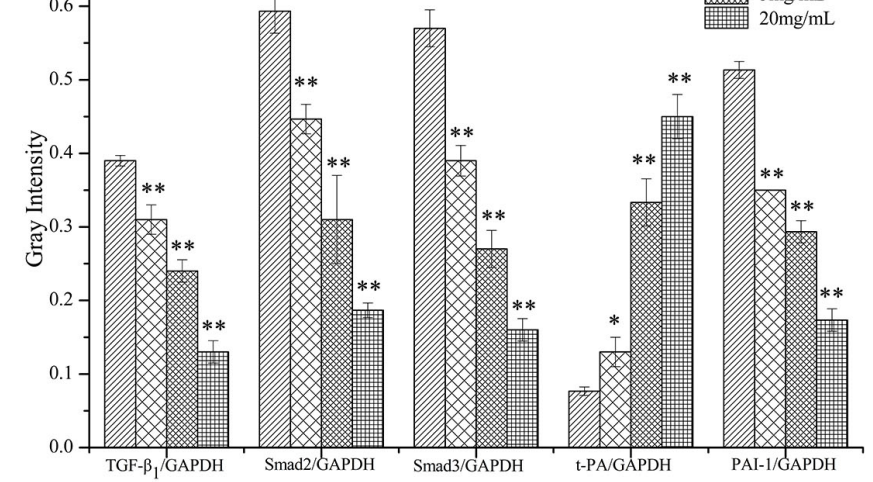

Fig. 4 Effects of SP-carboxymethyl chitosan on gene expression in the TGF- $\beta_{1} /$ Smad signaling pathway by Western blot. Gel electrophoresis and gray intensity analysis; * $p<0.05$ and $* * p<0.01$ versus control group.

tionally, both Smad2 and Smad3 were downregulated in all SP-carboxymethyl chitosan-treated compared to the control. When the SP-carboxymethyl chitosan concentration reached $1.25 \mathrm{mg} / \mathrm{ml}$, the expressions of TGF- $\beta_{1}$, PAI- 1 , Smad2, and Smad3 began to decrease significantly and continued to decrease with the increase of concentration. In contrast, t-PA was more extensively increased for all SPcarboxymethyl chitosan-treated groups compared to the control $(p<0.01)$. In particular, $20 \mathrm{mg} / \mathrm{ml}$ of SP-carboxymethyl chitosan displayed the most significant upregulation. Altogether, these data indicate that SP-carboxymethyl chitosan treatment regulates cell fibrogenesis by regulating genes in the TGF- $\beta_{1} /$ Smad signaling pathway.

To assess the inhibitory effect of SPcarboxymethyl chitosan treatment on cell fibrogenesis through the TGF- $\beta_{1} /$ Smad signaling pathway, the expression of proteins such as TGF- $\beta_{1}$, Smad2, Smad3, t-PA, and PAI-1 in cells was determined by Western blot (Fig. 4). SPcarboxymethyl chitosan treatment significantly decreased TGF- $\beta_{1}$, Smad2, Smad3, and PAI-1 protein expression in cells. When the SPcarboxymethyl chitosan concentration reached $1.25 \mathrm{mg} / \mathrm{ml}$, the protein expressions of TGF- $\beta_{1}$,
Smad2, Smad3, and PAI-1 began to decrease significantly and continued to decrease with the increase of concentration. By contrast, t-PA extensively increased for all SP-carboxymethyl chitosan-treated groups compared to the control. These results were consistent with those of RT-PCR and suggest a mechanism by which SPcarboxymethyl chitosan prevents cell fibrogenesis in L929 mouse fibroblasts.

\section{DISCUSSION}

Of the 600 types of chitin derivatives reported, carboxymethyl chitosan is the most widely studied. Carboxymethyl chitosans can be divided into Ncarboxymethyl chitosan, O-carboxymethyl chitosan and N,O-carboxymethyl chitosan [9]. China is the largest silk producer in the world, with an annual production of dry silkworm Bombyx mori pupae of over $10^{5}$ tons. In addition, the solubility of silkworm pupae chitosan in dilute acid is better than that of shrimp and crab chitosan which is suitable for the medical chitosan preparation [22]. In previous studies, we used silkworm pupae to create a novel silkworm pupae carboxymethyl chitosan (SP-carboxymethyl chitosan) [16] and demonstrated that it is effective in reducing postoperative 
adhesion in a rat cecal abrasion model [9]. To further elucidate its anti-adhesion mechanism, we studied the effect of SP-carboxymethyl chitosan on the proliferation of mouse L929 fibroblasts.

In the present study, the results of MTT assays and microscopic observation showed that the inhibition rate increased gradually with the increase of SP-carboxymethyl chitosan concentration. Moreover, TEM results showed that SP-carboxymethyl chitosan affected the morphology of mitochondria in fibroblasts. Overall, SP-carboxymethyl chitosan clearly inhibited the proliferation of mouse L929 fibroblasts.

TGF- $\beta_{1}$ plays a central role in a variety of fibrogenic processes, including ECM protein accumulation and glomerular fibrosis [23]. Moreover, TGF- $\beta_{1} /$ Smad signaling is a classic pathway that is activated during ECM production and transdifferentiation of tubular epithelial cells to fibroblasts [24]. The initiation process of TGF- $\beta_{1} / \mathrm{Smad}$ signaling pathway is as follows: T $\beta$ RI kinase is activated after TGF- $\beta_{1}$ binding to the membranebound TGF- $\beta_{1}$ type II receptor (T $\beta$ RII), resulting in the phosphorylation and activation of Smad2/3. The activated Smad2/3 proteins with Smad4 proteins form oligomeric complexes and translocate into nucleus, where they induce the expression of target genes, contributing to the development fibrosis [25]. Studies in vitro and in vivo have revealed TGF- $\beta_{1} /$ Smad signaling to be a significant mediator of fibrosis in many diseases such as renal fibrosis in diabetic nephropathy $[6,26-28]$ and endometriosis [29]. Previous study found that the expression of TGF- $\beta_{1}$ protein is upregulated in a rat cecal abrasion model, and treatment with SPcarboxymethyl chitosan suppresses TGF- $\beta_{1}$ expression [17]. In the present study, PCR and WB showed that SP-carboxymethyl chitosan treatment significantly decreased the expressions of TGF- $\beta_{1}$, Smad2, and Smad3 in fibroblasts. This suggests that SPcarboxymethyl chitosan may prevent postoperative adhesions by regulating the TGF- $\beta_{1} /$ Smad signaling pathway during cell fibrogenesis.

Additionally, the balance between PAI-1 and t-PA has been demonstrated to be important in regulating the development of adhesions which can express the balance between antifibrinolytic and fibrinolysis activity [30, 31]. Song et al [7] prepared a hydrogel composed of N,O-carboxymethyl chitosan (NOCC) and aldehyde hyaluronic acid (AHA), and assessed its anti-adhesion effect in a severe recurrent adhesion model. One of their findings was that, compared to the control group, the blood and abdominal lavage level of t-PA was increased in the NOCC-AHA hydrogel group, but there were no differences in PAI-1. In the present study, PCR and WB showed that SP-carboxymethyl chitosan treatment significantly decreased the expression of PAI-1, and it continued to decrease with the increase of concentration. In contrast, t-PA was extensively increased for all SP-carboxymethyl chitosan-treated groups compared to the control.

In summary, we conclude that SPcarboxymethyl chitosan inhibits the proliferation of mouse L929 fibroblasts, at least in part, by suppressing the TGF- $\beta_{1} /$ Smad signaling pathway. Based on previous and current research results, it is clear that SP-carboxymethyl chitosan can effectively inhibit the occurrence of postoperative adhesions. This study suggests that SP-carboxymethyl chitosan may prove to be very useful as a biomaterial to produce high-quality and scalable anti-adhesion products.

Acknowledgements: This study was supported by Shandong Provincial Natural Science Foundation, China (ZR2018LC020, ZR2016YL024).

\section{REFERENCES}

1. Mais V, Cirronis MG, Peiretti M, Ferrucci G, Cossu E, Melis GB (2012) Efficacy of auto-crosslinked hyaluronan gel for adhesion prevention in laparoscopy and hysteroscopy: a systematic review and meta-analysis of randomized controlled trials. Eur J Obstet Gyn R B 160, 1-5.

2. Zhu L, Peng L, Zhang YQ (2015) The processing of chitosan and its derivatives and their application for postoperative anti-adhesion. Mini-Rev Med Chem 15, 330-337.

3. Cheong YC, Shelton JB, Laird SM, Li TC, Ledger WL, Cooke ID (2003) Peritoneal fluid concentrations of matrix metalloproteinase-9, tissue inhibitor of metalloproteinase-1, and transforming growth factor-beta in women with pelvic adhesions. Fertil Steril 79, 1168-1175.

4. Cahill RA, Wang JH, Soohkai S, Redmond HP (2006) Mast cells facilitate local VEGF release as an early event in the patho-genesis of postoperative peritoneal adhesions. Surgery 140, 108-112.

5. Zheng ZJ, et al (2013) Influence of the carboxymethyl chitosan anti-adhesion solution on the TGF- $\beta_{1}$ in a postoperative peritoneal adhesion rat. $J$ Mater Sci: Mater Med 24, 2549-2559.

6. Yao L, et al (2019) Coreopsis tinctoria Nutt ameliorates high glucose-induced renal fibrosis and inflammation via the TGF- $\beta_{1} /$ SMADS/AMPK/NF-Îž B pathways. BMC Complem Altern M 19, ID 14. 
7. Song LJ, et al (2016) Peritoneal adhesion prevention with a biodegradable and injectable N,Ocarboxymethyl chitosanaldehyde hyaluronic acid hydrogel in a rat repeated-injury model. Sci Rep 6, ID 37600 .

8. Tokuyasu K, Ohnishi KM, Hayashi K (1996) Purification and characterization of extracellular chitin deacetylase from Colletotrichum lindemuthianum. Biosci Biotech Biochem 60, 1598-1603.

9. Upadhyaya L, Singh J, Agarwal V, Tewari RP (2013) Biomedical applications of carboxymethyl chitosans. Carbohydr Polym 91, 452-466.

10. Higham AP, Ringoood NJ, Posey Dowty DJ, Kingsport $\mathrm{T}$ (1991) Use of derivatives of chitin soluble in aqueous solutions for preventing adhesions. US Patent 005093319A.

11. Chen XG, Wang Z, Liu WS, Park HJ (2002) The effect of carboxymethyl-chitosan on proliferation and collagen secretion of normal and keloid skin fibroblasts. Biomaterials 23, 4609-4614.

12. Feng C, et al (2011) The effect of carboxymethylchitosan nanoparticles on proliferation of keloid fibroblast. Front Chem Chin 6, 31-37.

13. Xia QH, Liu ZW, Wang CH, Zhang ZX, Xu SS, Han CC (2015) A biodegradable trilayered barrier membrane composed of sponge and electrospun layers: hemostasis and antiadhesion. Biomacromolecules 16, 3083-3092.

14. Zahir-Jouzdani F, et al (2018) Chitosan and thiolated chitosan: Novel therapeutic approach for preventing corneal haze after chemical injuries. Carbohyd Polym 179, 42-49.

15. Zhou J, Elson C, Lee TDG, Scotian N (2004) Reduction in postoperative adhesion formation and reformation after an abdominal operation with the use of N,O-carboxymethyl chitosan. Surgery 135, 307-312.

16. Zhou J, Liwski RS, Elson C, Lee TDG (2008) Reduction in postsurgical adhesion formation after cardiac surgery in a rabbit model using N,O-carboxymethyl chitosan to block cell adherence. $J$ Thorac Cardiov Sur 135, 777-783.

17. Krause TJ, Zazanis G, Malatesta P, Solina A (2001) Prevention of pericardial adhesions with N-O carboxymethyl chitosan in the rabbit model. $J$ Invest Sur 14, 93-97.

18. Daroz LRD, Lopes JB, Dallan LAO, Campanafiho SP, Moreir LFP, Stolf NAG (2008) Prevention of postoperative pericardial adhesions using thermal sterile carboxymethyl chitosan. Rev Bras Cir Cardiovasc 23,
$480-487$.

19. Lopes JB, et al (2010) Synergism between keratinocyte growth factor and carboxymethyl chitosan reduces pericardial adhesions. Ann Thorac Surg 90, 566-572.

20. Zhu L, et al (2018) Properties of a novel carboxymethyl chitosan derived from silkworm pupa. Arch Insect Biochem Physiol 99, ID e21499.

21. Zhu L, Zhang YQ (2016) Postoperative anti-adhesion ability of a novel carboxymethyl chitosan from silkworm pupa in a rat cecal abrasion model. Mat Sci Eng C 61, 387-395.

22. Xiong YF, Chen HX (1998) Comprehensive utilization of silkworm chrysalis. Nat Prod Res Dev 10, 82-86.

23. Lan HY (2011) Diverse roles of TGF-beta/Smads in renal fibrosis and inflammation. Int $J$ Biol Sci 7, 1056-1067.

24. Wang Z, et al (2017) Role of endothelial-tomesenchymal transition induced by TGF-beta1 in transplant kidney interstitial fibrosis. J Cell Mol Med 21, 2359-2369.

25. Huang C, et al (2013) Blockade of KCa3.1 ameliorates renal fibrosis through the TGF- $\beta_{1} /$ Smad pathway in diabetic mice. Diabetes 62, 2923-2934.

26. Wu JS, Shi R, Lu X, Ma YM, Cheng NN (2015) Combination of active components of xiexin decoction ameliorates renal fibrosis through the inhibition of NF- $\kappa$ B and TGF- $\beta_{1} /$ Smad pathways in $\mathrm{db} / \mathrm{db}$ diabetic mice. Plos One 10, ID e0122661.

27. Yao L, et al (2015) The anti-inflammatory and antifibrotic effects of Coreopsis tinctoria Nutt on highglucose-fat diet and streptozotocin-induced diabetic renal damage in rats. BMC Complem Altern M 15, ID 314.

28. Li Z, Hong Z, Peng Z, Zhao Y, Shao R (2018) Acetylshikonin from Zicao ameliorates renal dysfunction and fibrosis in diabetic mice by inhibiting TGF$\beta_{1} /$ Smad pathway. Human Cell 31, 199-209.

29. Lin $X$, et al (2018) Hypoxia promotes ectopic adhesion ability of endometrial stromal cells via TGF$\beta_{1} /$ Smad signaling in endometriosis. Endocrinology 159, 1630-1641.

30. Falk K, Bjorquist P, Stromqvist M, Holmdahl L (2001) Reduction of experimental adhesion formation by inhibition of plasminogen activator inhibitor type 1 . Br J Surg 88, 286-289.

31. Binda MM, Molinas CR, Koninckx PR (2003) Reactive oxygen species and adhesion formation: clinical implications in adhesion prevention. Hum Reprod 18, 2503-2507. 